\section{Ferrihydrite transformation in flooded paddy soil microcosms}

\author{
ANDREW R. C. GRIGG ${ }^{1}$, KATRIN SCHULZ ${ }^{1}$, KATHERINE \\ A. ROTHWELL ${ }^{1}$, RALF KAEGI ${ }^{2}$, LAUREL KATHLEEN \\ THOMAS ARRIGO ${ }^{1}$ AND RUBEN KRETZSCHMAR ${ }^{1}$ \\ ${ }^{1}$ ETH Zurich \\ ${ }^{2}$ Eawag, Swiss Federal Institute of Aquatic Science and \\ Technology
}

Presenting Author: andrew.grigg@usys.ethz.ch

Iron minerals are abundant in soils and undergo transformations that have the potential to immobilise or remobilise trace elements in redox dynamic environments [1]. Often, mineral transformation studies employ slurries or coatings on inert materials, but transformation is rarely studied in soils due to experimental challenges. Here, we introduced synthetic ferrihydrite to soil microcosms in permeable polyethylene terephthalate fabric sachets (sachet dimension approximately 30 $\mathrm{mm} \times 12 \mathrm{~mm} \times 3 \mathrm{~mm}$ with $52 \mu \mathrm{m}$ pore size). The microcosms contained five contrasting rice paddy soils from Bangladesh, China and Thailand, which were flooded to simulate conditions at the start of a rice growing season. Mineral transformations and pore water chemistry were measured after one, two, six and twelve weeks. The mineral composition inside the sachets was measured using X-ray diffraction (bulk, all time points) and micro-Raman spectroscopy (micrometre scale resolution, two weeks only). Bulk analysis showed that lepidocrocite and goethite gradually replaced ferrihydrite in the sachets that were buried in redox-active soils. The transformation rate of ferrihydrite and the product composition varied between soils and within sachets, reflecting variations in concentrations of key species in pore water. Higher $\mathrm{Fe}^{2+}$ and $\mathrm{SO}_{4}{ }^{2-}$ concentrations in solution were not only associated with faster bulk transformation rates, but also higher bulk ratios of lepidocrocite to goethite. At the sub-millimetre scale, transformation rates were different to bulk transformation rates, as observed in the colour distribution (Figure 1, microscope image of partial cross-section) and microRaman spectroscopy maps across mineral sachet cross-sections. Ferrihydrite was observed at the soil-mineral interface, suggesting that chemical species in the porewater inhibited transformation of the outer mineral layer. Ferrihydrite was also observed in the interior, where $\mathrm{Fe}^{2+}$ was less able to diffuse from the soil. At the micrometre scale, transformed regions were made up of inhomogeneous clusters of ferrihydrite, goethite and lepidocrocite. The distribution of minerals in the sachets demonstrates that local environmental conditions and global soil properties have measurable impacts on the rate and pathway of ferrihydrite transformation.

[1] Borch, Kretzschmar, Kappler, Van Cappellen, GinderVogel, Voegelin and Campbell (2010), Environ. Sci. Technol. 44, 15-23.

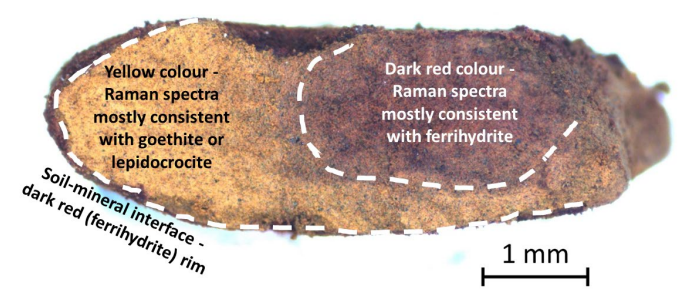

$1 \mathrm{~mm}$ 